This item was submitted to Loughborough's Research Repository by the author.

Items in Figshare are protected by copyright, with all rights reserved, unless otherwise indicated.

\title{
Simulation study on the measured difference in fuel consumption between real-world driving and ECE-15 of a hybrid electric vehicle
}

PLEASE CITE THE PUBLISHED VERSION

http://dx.doi.org/10.1049/cp.2013.1918

\section{PUBLISHER}

Institute of Engineering Techonology (IET)

VERSION

AM (Accepted Manuscript)

\section{LICENCE}

CC BY-NC-ND 4.0

\section{REPOSITORY RECORD}

Lintern, Matthew A., Rui Chen, S. Carroll, and Chris Walsh. 2014. "Simulation Study on the Measured Difference in Fuel Consumption Between Real-world Driving and ECE-15 of a Hybrid Electric Vehicle". figshare. https://hdl.handle.net/2134/15620. 


\title{
Simulation study on the measured difference in fuel consumption between real-world driving and ECE-15 of a hybrid electric vehicle
}

\author{
M A Lintern*, R Chen*, S Carroll ${ }^{\dagger}$, C Walsh ${ }^{\dagger}$ \\ ^Loughborough University, United Kingdom, E-mail: R.Chen@lboro.ac.uk, \\ ${ }^{+}$Cenex, United Kingdom, E-mail: Chris.Walsh@cenex.co.uk
}

Keywords: HEV, real-world, driving, cycle, fuel.

\begin{abstract}
Hybrid electric vehicles (HEVs) are sensitive to the driving conditions under which they are used, leading to greater fuel consumption than quoted by the manufacturer, and therefore higher $\mathrm{CO}_{2}$ emissions. Real-world driving can be very different from the legislative drive cycles as speeds are greater, there are faster changes in speed, and these changes occur at a greater frequency. This study aims to investigate where the differences between real-world driving and the ECE-15 urban drive cycle occur through development of a real-world drive cycle and via a system simulation study. A second generation 2004 Toyota Prius equipped with a GPS (Global Positioning System) data logging system was used to collect data while in use by Loughborough University Security over a period of 9 months. These data were used for the development of a drive cycle, Loughborough University Urban Drive Cycle (LUUDC), representing urban driving around the university campus and local urban area. The same vehicle was tested on a chassis dynamometer on the LUUDC against the ECE-15 cycle and others. Fuel consumption was measured and $\mathrm{CO}_{2}$ emissions were calculated and compared. A model based on Autonomie vehicle simulation software was used to simulate and analyse the differences. The test and modelling results showed higher fuel consumption on LUUDC than ECE-15. The reasons for this will be discussed in this paper.
\end{abstract}

\section{Introduction}

\subsection{Background}

Low carbon vehicles including hybrids are becoming more popular due to factors such as the increasing cost of fuel and concerns about environmental issues. Users of hybrid vehicles report higher fuel consumption during use than the manufacturer states [1] so research is required into why this is the case.

A HEV is a vehicle that uses two power sources, in this case a petrol internal combustion engine (ICE) and two electric machines. The Toyota Prius has a power-split planetary gear transmission system providing power mechanically and electrically.

\subsection{Aims and objectives}

This investigation aims to establish fuel consumption and corresponding $\mathrm{CO}_{2}$ emissions of a hybrid vehicle in realworld application. From GPS data collected in a test vehicle whilst in use, a drive cycle representative of urban driving will be developed. The difference in fuel consumption and $\mathrm{CO}_{2}$ emissions between real-world driving and legislative drive cycles will be quantified, and the reasons for the differences investigated.

\section{Methodology}

\subsection{Vehicle and equipment}

A 2004 Toyota Prius was used as a research test vehicle; details on this vehicle can be seen in the literature [2]. It was equipped with an ICP-CON GT-540 GPS data logger with an analogue input module connected with 8 inputs. Connected to this were Isaac sensors installed on the high voltage (HV) battery pack. A SENVDC-251 250v voltage sensor and SENADC-301 +/-300A current transducer measured the voltage and current in and out of the battery respectively. The vehicle was equipped with quick-release fuel connections so that a Corrsys Datron DFL 1x-5bar Coriolis fuel flow meter could be temporarily installed during chassis dynamometer testing.

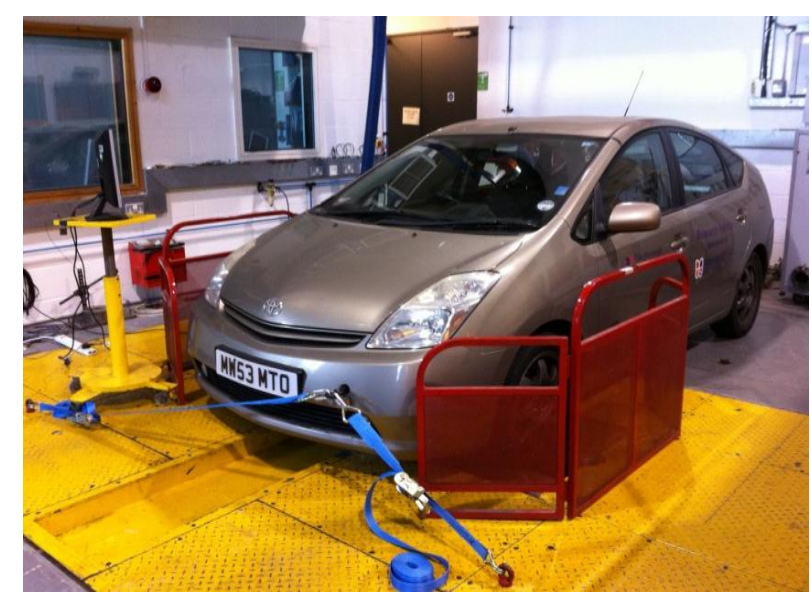

Figure 1: Toyota Prius test vehicle on chassis dynamometer. 


\subsection{Real-world test}

The vehicle was put into use with Loughborough University Security department for 9 months as one of their regular patrol vehicles. It was driven mainly around the campus and had some use in the local area, so the driving was all urban. This testing is relevant to various other similar usages within an urban environment, for example a delivery vehicle or commuting.

The fuel consumption was recorded on mileage and fuel log sheets which were used to calculate the average fuel consumption during testing. The corresponding $\mathrm{CO}_{2}$ emissions were estimated from the amount of fuel used. This was done by multiplying the carbon content of the fuel by an oxidation factor to account for the small proportion of fuel that was not oxidised into $\mathrm{CO}_{2}$, and by the ratio of the molecular mass of $\mathrm{CO}_{2}$ to the molecular mass of carbon. These parameters are as follows:

- Carbon content of a US gallon of gasoline $2421 \mathrm{~g}$ [3]

- Carbon content of a litre of gasoline $\quad 639.6 \mathrm{~g}$

- Oxidation factor for oil products

- Molecular mass of $\mathrm{CO}_{2}$ 44

- Molecular mass of carbon
$\mathrm{CO}_{2}$ emissions $(\mathrm{g} /$ litre $)=$

$639.56 * 0.99 *(44 / 12)=2321.6 \mathrm{~g} /$ litre.

The $\mathrm{CO}_{2}$ emissions in the standard form of $\mathrm{g} / \mathrm{km}$ were then calculated using the result of Equation (1) as follows in Equation (2).

$\mathrm{CO}_{2}$ emissions $(\mathrm{g} / \mathrm{km})=$

(Fuel cons. in 1/100 km /100)*2321.6

The data were grouped into weeks and into months by periods determined by time between refuelling points, rather than calendar periods, so that fuel consumption during these periods could be calculated. These were chosen keeping the month's duration as even as possible between all months.

\subsection{Chassis dynamometer test}

In order to model the vehicle for the chassis dynamometer, coastdown tests were carried out at MIRA Proving Ground. Ten runs were driven in each direction on the parallel straights starting from $100 \mathrm{~km} / \mathrm{h}$, putting the transmission into neutral and allowing the vehicle to slow down to $0 \mathrm{~km} / \mathrm{h}$. A MATLAB programme was written to interpolate the speedtime data at $5 \mathrm{~km} / \mathrm{h}$ decrements to calculate the corresponding gatetimes, which are the measured times taken between the speed points. Pairs of runs in opposite directions were averaged, then these ten sets were averaged to give overall gatetimes that were used in the dynamometer coastdown model for producing a speed-time curve.

For chassis dynamometer testing the following procedure was carried out:

1. Check tyre pressures $\&$ adjust if necessary
2. Warm up dynamometer rollers at $80 \mathrm{~km} / \mathrm{h}$ for 45 minutes 3. Carry out dynamometer calibration (only at the start of a test period/week) - This measures inertia, friction and windage losses in the system so that they are accounted for in the applied force to give an accurate force at the rollers' surface

4. Position vehicle on rollers

5. Disable vehicle traction control to allow the front wheels to be driven without the rear wheels turning

6. Warm up vehicle engine, tyres and transmission on rollers by driving at a constant $80 \mathrm{~km} / \mathrm{h}$ for 30 minutes

7. Carry out vehicle calibration - This is done to force the dynamometer speed to match the vehicle coastdown curve

8. Driving vehicle to condition HV battery at $115 \mathrm{~km} / \mathrm{h}$ for 15 minutes

9. Run drive cycle tests

The LUUDC was tested along with the NEDC and ECE-15 to analyse the differences. The FTP and Artemis Urban were also tested for comparison. As battery state of charge (SoC) measuring instrumentation was not available, before running a drive cycle the vehicle was driven for 15 minutes at a constant $115 \mathrm{~km} / \mathrm{h}$, in order to condition the battery so that it was at a similar level at the start of each different drive cycle test. This speed which is equivalent to motorway cruising speed was used as it allowed the HV battery to be charged to provide a high SoC starting point. For each cycle four runs were carried out back-to-back to allow for experimental differences. The setup is shown below in Figure 2.

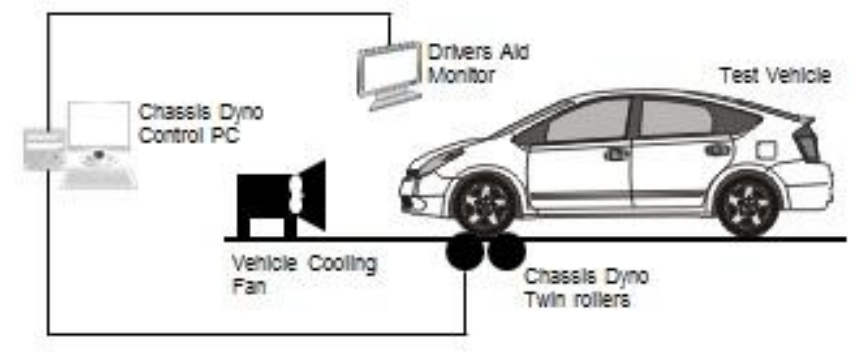

Figure 2: Diagram of chassis dynamometer setup. Diagram produced using images from [4] [5].

During testing the HV battery current and voltage and fuel flow were logged by the vehicle instrumentation as described in Section 2.1. As $\mathrm{CO}_{2}$ emissions measurement equipment was not available this was estimated from the fuel consumption as described in Section 2.2. As vehicle speed is usually measured by GPS so could not be recorded by the vehicle, the chassis dynamometer logged this at the rollers. This meant that there were two simultaneous data files that had to be combined. This was done by matching the increase in current drawn from the HV battery as the vehicle starts to move, to the start of the speed trace.

Estimated SoC levels were calculated for each drive cycle test using the voltage method, in which a battery discharge curve (voltage against SoC) is used to find the SoC at a particular $\mathrm{HV}$ battery voltage. The shortcoming of this method is that 
the voltage is affected by the battery current and temperature. Additionally, as a battery degrades its discharge pattern will change, therefore not following the same curve.

\subsection{Simulation test}

Autonomie was used to run simulations. It is a forwardlooking vehicle simulation software based on MATLAB that can be used to evaluate a vehicle's performance. The in-built 2004 Prius model was used, as shown in Figure 3, with some parameters edited. The mass was set as $1375 \mathrm{~kg}$ (the mass of our test vehicle weighed at MIRA), and the initial SoC was set at $60 \%$ as this is the target level that the Prius battery management system aims to maintain [6]. Tests were run on the same set of cycles as for the chassis dynamometer tests but just one run was carried out as the simulations are repeatable every time.

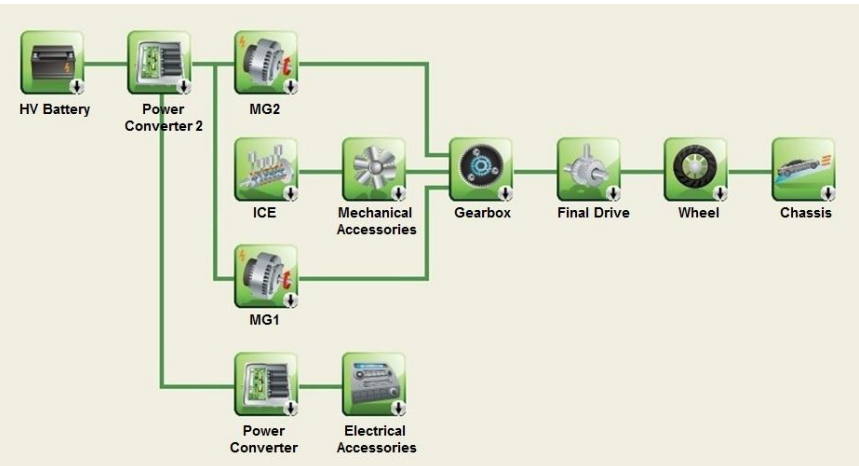

Figure 3: Autonomie simulation software 2004 Prius model.

\section{Drive cycle development}

The majority of the time spent on this study was in the development of the Loughborough University Urban Drive Cycle (LUUDC). GPS data logged while the vehicle was in use was processed to develop the cycle. Cenex's Fleet Carbon Reduction Tool (FCRT) was used to generate the drive cycle. FCRT splits recorded drive data into micro-cycles. Each micro-cycle is a continuous length of drive data that meets predefined criteria to represent a specific road type (e.g. urban, road, motorway). The micro-cycles are then pooled to create a shorter drive cycle which is statistically representative of the larger set of drive data. Since a very short cycle (circa 0.5 hours) was required for dynamometer testing, and the drive data was dominated by the urban road type, the maximum length of each micro-cycle was defined within the software. A validation exercise comparing the drive cycles created by FCRT showed that representative cycles could be created when the maximum cycle duration was less that $30 \%$ of the target drive cycle duration. The final cycle produced used a maximum micro-cycle length which was $10 \%$ of the target cycle length.

The raw CSV (comma-separated values) data files from the data logger required reformatting and screening before they could be entered into the Cenex FCRT. Screening involved smoothing speed jumps which were caused by GPS errors and setting a realistic maximum idle time, as the data logger reported ignition state and but not idling. The reformatting and screening procedure was automated in MATLAB and is described in the flow chart in Figure 4 below.

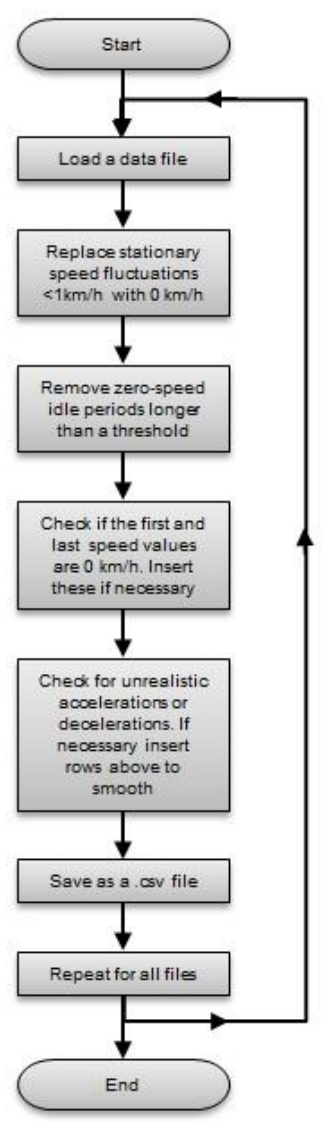

Figure 4: Flow chart of MATLAB programme.

Below in Figure 5 is the final drive cycle constructed within FCRT.

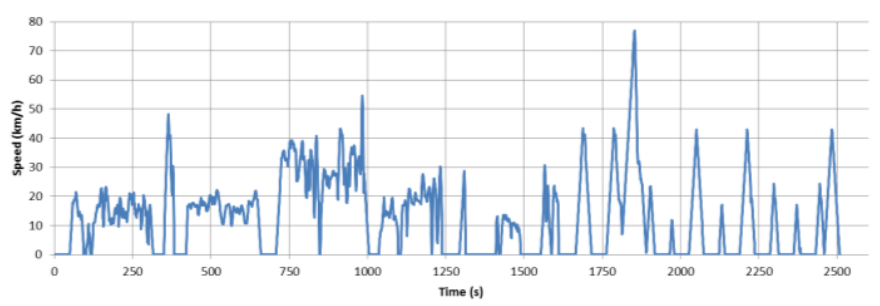

Figure 5: Loughborough University Urban Drive Cycle (LUUDC).

The other drive cycles tested are shown in Figure 6, Figure 7, Figure 8 and Figure 9. The legislative test cycle used in Europe is the NEDC which is made up of four repeated urban ECE-15 Urban Drive Cycles (UDC) and one Extra-Urban Drive Cycle (EUDC). These cycles follow a regular linear pattern whereas the US Federal Test Procedure (FTP) and Artemis Urban Cycle are much more transient with a greater frequency of accelerations and decelerations. It can be seen that the LUUDC is more similar to these latter cycles. 


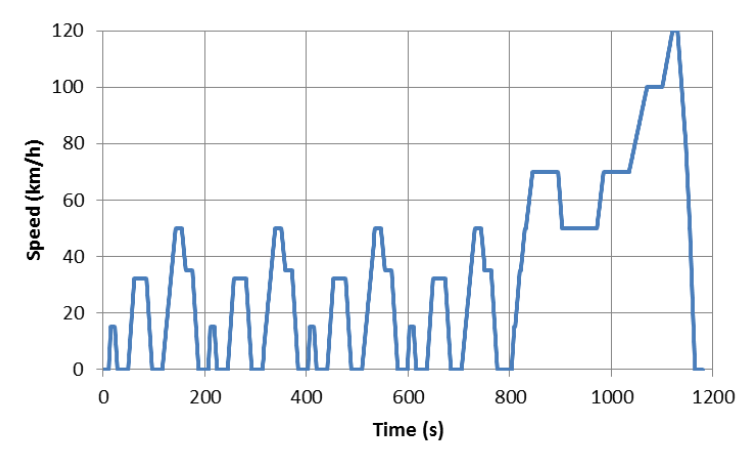

Figure 6: New European Drive Cycle (NEDC).

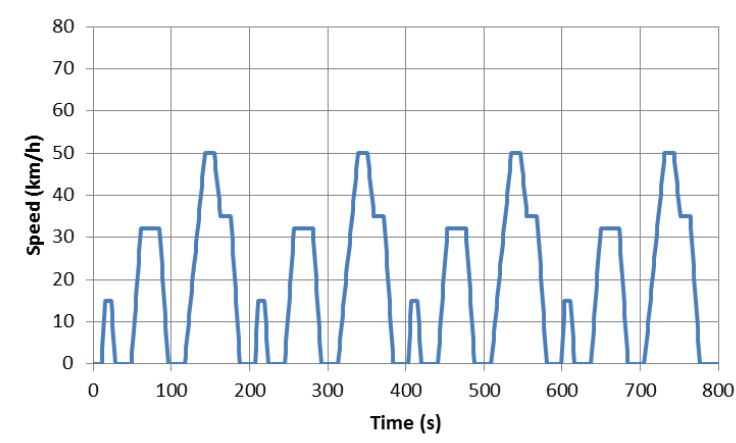

Figure 7: ECE-15 urban drive cycle.

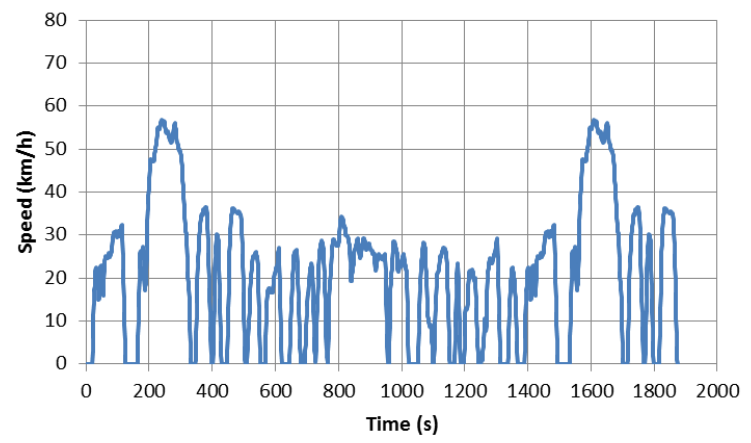

Figure 8: Federal Test Procedure (FTP) drive cycle.

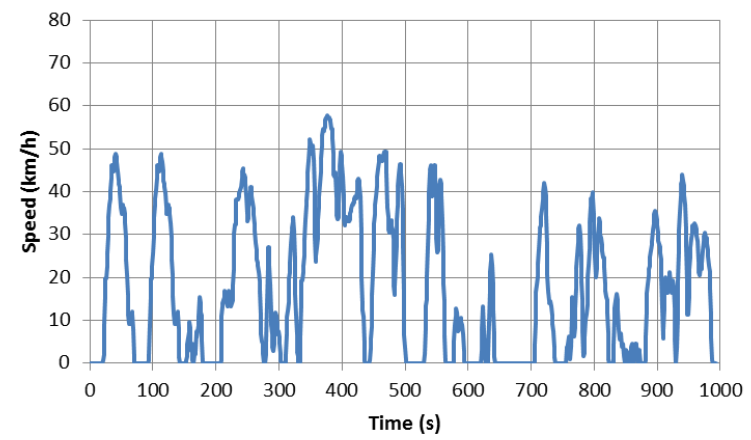

Figure 9: Artemis Urban Cycle.

\section{Results}

\subsection{Real-world testing results}

During the test period the vehicle covered a total of 11330 miles $(18233 \mathrm{~km})$ over 242 days. The results for the test period are shown in Figure 10. The fuel consumption shows an increasing and decreasing trend over time, with the $\mathrm{CO}_{2}$ emissions showing the same trend due to being calculated from the fuel consumption. The directions of the two lines on the plot are in opposite directions due to the units used. The month-on-month variation could be due to different vehicle usage.

The overall average fuel consumption for the period was 42.7 mpg $(6.61 \mathrm{l} / 100 \mathrm{~km})$ with estimated $\mathrm{CO}_{2}$ emissions of 153.5 $\mathrm{g} / \mathrm{km}$. These are shown on the chart as dotted lines for reference.

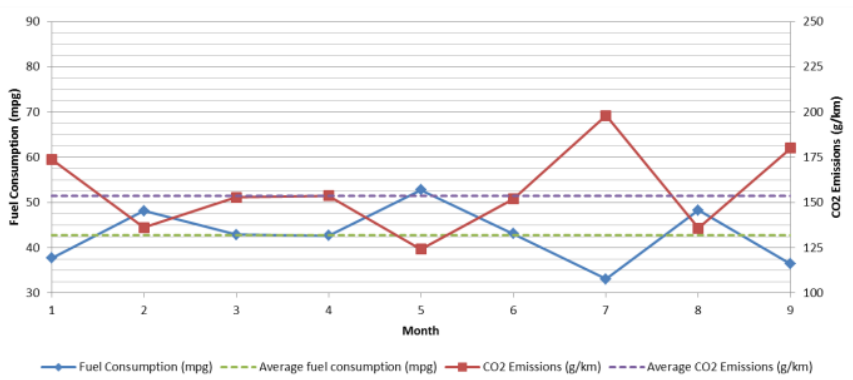

Figure 10: Results of real-world testing.

\subsection{Chassis dynamometer test results}

Figure 11 shows the fuel consumption results from the chassis dynamometer testing for each of the drive cycles tested which were LUUDC, NEDC, ECE-15, FTP and Artemis Urban. It can be seen that the fuel consumption of the first run is lower than the subsequent runs, particularly in the case of the ECE15 , and the fuel consumption for run 2 to run 4 is quite stable.

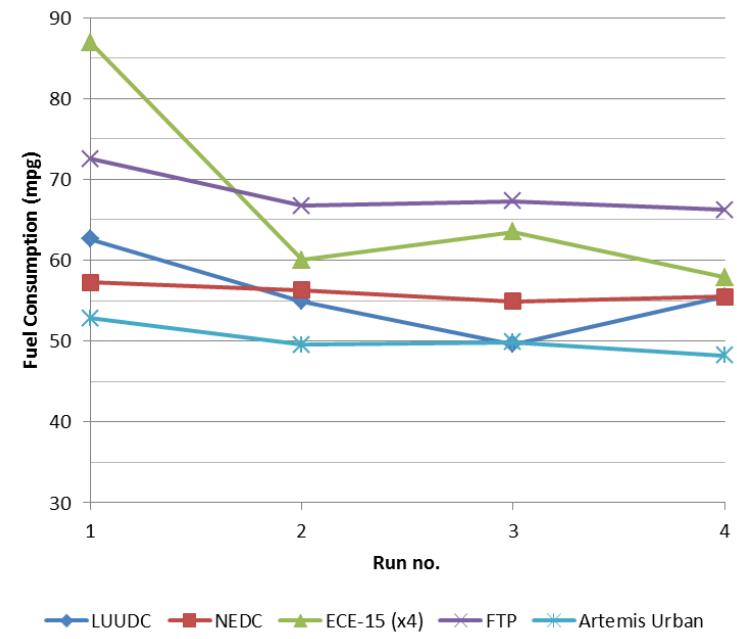

Figure 11: Results of chassis dynamometer testing.

The lower fuel consumption for run 1 will be due to the higher initial SoC level attained by doing the pre- 
conditioning. Therefore this will have allowed the vehicle to be driven by the electric motors for more of the drive cycle and used the ICE less. The stability of the results of the subsequent runs indicates that after the first run the $\mathrm{SoC}$ is at a similar level at the start of each of these tests. From this finding, run 1 was discarded and the average of runs 2, 3 and 4 were taken as the final results for the chassis dynamometer tests.

The estimated $\mathrm{CO}_{2}$ emissions were calculated and the percentage difference in fuel consumption between each cycle and the LUUDC is shown in Table 1. The values show the results for the LUUDC are similar to the NEDC with only a $4.1 \%$ increase in fuel consumption. The LUUDC does not contain high speed driving so is more comparable to the ECE15 urban drive cycle, so it forms a more useful comparison for results. There is a more significant difference with $11.8 \%$ greater fuel consumption than the ECE-15. This difference will be due to the transient nature of the LUUDC with its high frequency of changes in speed, plus they are more aggressive. Having constant speed periods in the ECE-15 allowed the vehicle to run in a more efficient operating mode. The gradual linear accelerations on the ECE-15 meant that the vehicle could be driven electrically more so than on the LUUDC, where the harsher accelerations required the ICE to provide more propulsion power.

\begin{tabular}{|c|c|c|c|c|}
\hline Drive Cycle & Fuel Cc & umption & CO2 Emissions & Difference to \\
\hline LUUDC & 53.34 & 5.30 & 122.95 & $0.0 \%$ \\
\hline NEDC & 55.60 & 5.08 & 117.96 & $-4.1 \%$ \\
\hline ECE-15 (x4) & 60.47 & 4.67 & 108.45 & $-11.8 \%$ \\
\hline FTP & 66.76 & 4.23 & 98.23 & $-20.1 \%$ \\
\hline Artemis Urban & 49.20 & 5.74 & 133.29 & $8.4 \%$ \\
\hline
\end{tabular}

Table 1: Results of chassis dynamometer testing using average fuel consumption of runs 2 to 4 with the difference between each cycle compared to LUUDC.

The largest difference was with the FTP, the LUUDC fuel consumption was $20.1 \%$ lower. In contrast, the LUUDC was $8.4 \%$ better than the Artemis Urban cycle which gave the lowest figure of the tests.

The fuel consumption for the duration of the vehicle's road test period was $42.7 \mathrm{mpg}$, as discussed earlier in Section 5.1, which is $19.9 \%$ less than that recorded during the chassis dynamometer testing on the LUUDC which should be equivalent. There are several factors not accounted for in the generation of the drive cycle that could account for this difference, including tyre pressures, vehicle loading, and gradients. Since the vehicle only usually carries a driver and sometimes one passenger, and as the speeds travelled at are low, loading and tyre pressures will not be significant in this case. Gradient is thought to be important out of these factors, as there are several across Loughborough University campus including two long gradual slopes and a short steep hill, therefore these could be a significant contributor. Whereas on a flat road in a situation where the vehicle could run in electric only mode, on an incline the ICE could be required to drive the vehicle at the same speed or acceleration, leading to increased fuel use. The effect of gradient will be investigated in future work to validate this theory.

The calculated SoC levels at the start and end of each run of a drive cycle appeared not to be accurate because many are in the $20-40 \%$ region which is below the usual operating range of the Prius (50-70\% [6]) and some values were as high as $92 \%$, again beyond this region. Additionally for some tests there was a significant difference of up to $34 \%$ between the level at the end of a run compared to at the start of the following successive run, where there should not have been a significant change as the vehicle was switched off during this time. Due to the apparent inaccuracy of the values they were not used in the analysis. It is likely that the test vehicle's battery will have degraded due to the number of cycles it has undergone due to its age and mileage so the discharge curve used from Autonomie will not reflect the battery in its current state.

\subsection{Autonomie simulation results}

The results of simulations run over the same drive cycles as for the chassis dynamometer tests are shown in Table 2 .

\begin{tabular}{|l|c|c|c|}
\hline \multirow{2}{*}{ Drive Cycle } & \multicolumn{2}{|c|}{ Fuel Consumption } & CO2 Emissions \\
& $\mathbf{m p g}$ & $\mathbf{l} / \mathbf{1 0 0} \mathbf{k m}$ & $\mathbf{g} \mathbf{k m}$ \\
\hline LUUDC & 74.93 & 3.77 & 118.84 \\
\hline NEDC & 72.80 & 3.88 & 122.31 \\
\hline ECE-15 (x4) & 76.14 & 3.71 & 117.06 \\
\hline FTP & 89.68 & 3.15 & 99.45 \\
\hline Artemis Urban & 56.84 & 4.97 & 156.60 \\
\hline
\end{tabular}

Table 2: Results of simulation.

Figure 12 shows the results next to the chassis dynamometer test results. They follow the same trend but there are differences in the values with the simulations giving fuel consumption values $15-40 \%$ lower than the chassis dynamometer testing. There are two likely reasons for this, one of which is because of a difference in SoC levels between that at the start of the chassis dynamometer tests compared to the $60 \%$ used in the simulations being higher. The other possible reason for the difference is degradation of the HV battery on the test vehicle as previously mentioned. This could mean that the SoC depletes more quickly so requires more charging, or it could be linked to the previous point, in that the initial SoC is lower giving less available power before charging occurs. This would reduce the amount of electric drive assistance provided meaning the ICE has to be utilised more. These factors require investigation which will be done in future work.

In the simulation, over each of the drive cycles there was an increase in $\mathrm{SoC}$ in the range of $2-7.5 \%$. In the chassis dynamometer tests on runs 2 to 4 the indicated SoC on the vehicle display remained constant at either 5 or 6 bars out of 10 , except the last ECE-15 run where it increased from 5 bars to 6 bars. This would imply that the change in SoC is small, so similar to the simulation. 
For illustration the average fuel consumption over the duration of the real-world test is shown in Figure 12 next to the test results for the LUUDC which was discussed in the previous section.

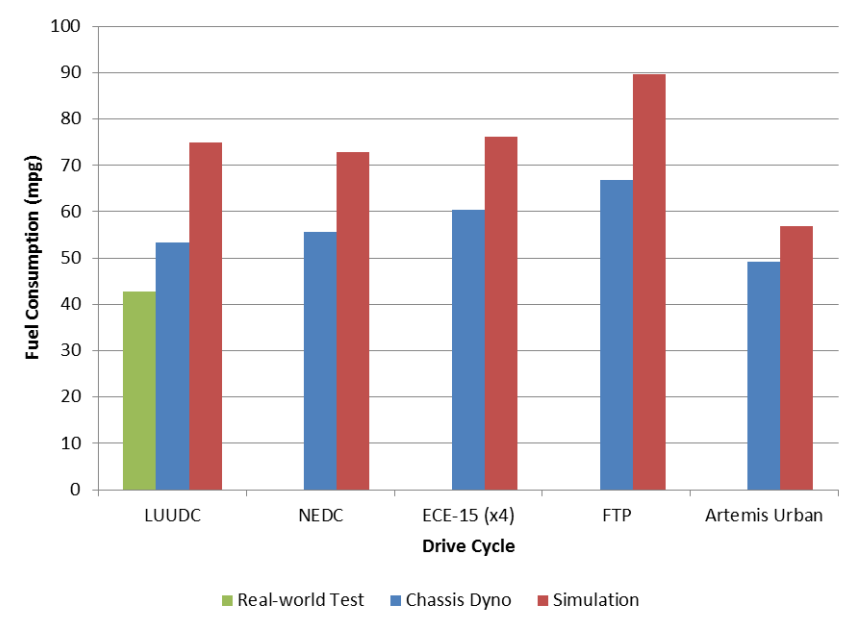

Figure 12: Comparison of fuel consumption for chassis dynamometer test, simulation and real-world test.

\section{Summary}

In this study the fuel consumption and $\mathrm{CO}_{2}$ emissions of a hybrid vehicle during real-world use in an urban application were calculated. A drive cycle was developed from data logged during the vehicle's use using MATLAB and Cenex's FCRT. The cycle is much more transient than the European legislative ECE-15 and NEDC; it has greater similarity to the FTP and Artemis cycles. This cycle was then used for testing on a chassis dynamometer and found that the fuel consumption in real-world use was $20 \%$ higher than the lab testing which is believed to be due to road gradients.

The LUUDC was compared to other cycles in testing and it was found that the fuel consumption and $\mathrm{CO}_{2}$ emissions were higher than the ECE-15. This was due to having many more changes in speed, coupled with more aggressive change in speed, in the developed cycle. Simulations were conducted to investigate the differences, which showed a similar trend but with lower fuel consumption than the chassis dynamometer tests. This is thought to be due to HV battery degradation and lower initial SoC in the test vehicle. These factors require additional investigation which will form further future work, along with the effects of gradient on drive cycles.

\section{Acknowledgements}

This work was supported by sponsorship from the Engineering and Physical Sciences Research Council (EPSRC) and Romax Technology. The authors would like to thank Kathryn Taylor and Stuart Chubbock of Romax Technology for their assistance in the production of this work with advice on data processing and vehicle modelling.

\section{References}

[1] http://grist.org/article/gas-mileage-consumer-retorts/, Accessed June 2013.

[2] K. Muta, M. Yamazaki, J. Tokieda. "Development of New-Generation Hybrid System THS II - Drastic Improvement of Power Performance and Fuel Economy", SAE World Congress, 2004, SAE Paper 2004-01-0064, (2004).

[3] United States Environmental Protection Agency (EPA) Office of Transportation and Air Quality. "Emission Facts: Average Carbon Dioxide Emissions Resulting from Gasoline and Diesel Fuel", EPA420-F-05-001, (2005).

[4] http://catalog.provehicleoutlines.com, Accessed July 2013.

[5] http://www.clker.com, Accessed July 2013.

[6] http://www.autoshop101.com/forms/Hybrid03.pdf, pp. 5, Accessed June 2013. 